University of Nebraska - Lincoln

DigitalCommons@University of Nebraska - Lincoln

Faculty Publications: Department of Entomology

6-1990

Feeding Behavior of Nephotettix virescens (Homoptera:

Cicadellidae) on Rice Varieties with Different Levels of Resistance

H. R. Rapusas

E. A. Heinrichs

Follow this and additional works at: https://digitalcommons.unl.edu/entomologyfacpub

Part of the Agriculture Commons, and the Entomology Commons

This Article is brought to you for free and open access by the Entomology, Department of at

DigitalCommons@University of Nebraska - Lincoln. It has been accepted for inclusion in Faculty Publications:

Department of Entomology by an authorized administrator of DigitalCommons@University of Nebraska - Lincoln. 


\title{
Feeding Behavior of Nephotettix virescens (Homoptera: Cicadellidae) on Rice Varieties with Different Levels of Resistance
}

\author{
H. R. Rapusas and E. A. Heinrichs* \\ International Rice Research Institute, Manila, Philippines \\ * Current address - Dept. of Entomology, 402 Life Sciences Bldg., Louisiana State University, Baton Rouge, LA 70803
}

\begin{abstract}
The feeding behavior of Nephotettix virescens (Distant) on rice varieties with different levels of resistance was studied using an AC electronic monitor for insect feeding (EMIF) system. Varieties used were TN1 (susceptible), IR36 (moderately resistant), and ASD7, IR60, and IR64 (resistant). Six typical waveforms were recorded, and each type corresponded to a certain activity of the insect during the feeding process as indicated by histological sections of the leaf observed. Significantly more phloem feeding was observed on the susceptible plants than on the moderately resistant and resistant plants. Fifty percent of the total test period was spent feeding on the susceptible variety and only $25 \%$ on the resistant varieties.
\end{abstract}

Keywords: Insecta, Nephotettix virescens, resistance, feeding behavior

The leafhopper Nephotettix virescens (Distant) is an important pest of rice throughout South and Southeast Asia. It damages the rice plant by sucking the plant sap and is the most efficient vector of rice tungro virus.

The feeding behavior of this insect is an important consideration in studying transmission of rice tungro virus. The insect can feed on the xylem and phloem sap, but studies have shown that it feeds mainly in the xylem on resistant plants and (after the first $3 \mathrm{~h}$ ) in the phloem on susceptible plants (Auclair et al. 1982). The ability of the insect to transmit the virus is positively correlated with the amount of phloem feeding, indicating that phloem 
feeding is necessary for rice tungro virus infection (Heinrichs \& Rapusas 1984). Thus, varieties resistant to $N$. virescens are a poor source of rice tungro virus inoculum in the field although such varieties may not be immune to the infection (Cabunagan et al. 1984).

The AC electronic monitor for insect feeding (EMIF) has been used to study probing, salivation, and ingestion by aphids (McLean \& Kinsey 1964, 1965; McLean 1977; Hodges \& McLean 1969; Nielson \& Don 1974) and by leafhoppers (Chang 1978). A similar system, fitted with a log amplifier, has been used to study the feeding behavior of the rice leafhopper Nephotettix cincticeps (Uhler) (Kawabe \& McLean 1982, Kawabe 1985) and Nilaparvata lugens (Stål) (Ve]usamy \& Heinrichs 1986). A DC-battery monitor has been used by Saxena \& Kahn (1985).

In this study, the feeding behavior of $N$. virescens on rice varieties with different levels of resistance to the insect was determined using the EMIF system. Site of feeding within leaf tissue as determined by the EMIF system was confirmed through histological examination.

\section{Materials and Methods}

Five rice varieties with different levels of resistance to $N$. virescens were used in this test. The test varieties were TN1 (susceptible-S); IR36 (moderately resistant-MR); and ASD7, IR60 and IR64 (resistant-R). Seven-day-old seedlings of the test varieties were planted in clay pots (12 cm diameter) and placed in a water tray in the greenhouse. Plantings were staggered to provide a steady supply of 20 - to 30 -d-old plants throughout the experimental period.

Test insects were obtained from a colony reared on TN1 for about 30 generations in the greenhouse. Ten insects were used for each variety, and each insect was tested for $3 \mathrm{~h}$.

\section{Preparation of the Insects}

The insects were first anesthetized with carbon dioxide gas. Then, before the insect recovered, one end of a gold wire ( $20 \mu$ diameter and about $5 \mathrm{~cm}$ long) was attached to the dorsum of the insect with electroconductive paint (Dotite D-550). The other end of the gold wire was connected to the EMIF system, and the insect was placed on the leaf of a potted rice plant, which was connected to the system (Kawabe \& McLean 1982).

The EMIF system used in this study consisted of a strip chart recorder, an oscilloscope, and an actgraph ME-1221 (Medical Electronic Commercial Company, Tokyo) (Kawabe et al. 1981). The actgraph recorded variations of electrical conductance, between the plant and insect, during feeding through a current-sensitive amplifier. An oscillator on the actgraph provided a high frequency AC signal that prevented responses by the insect to the current applied to the plant. Also, it minimized problems of electrical noise generated by other electrical equipment in the vicinity. Oscillation voltage was $0.5 \mathrm{~V}$ and signal frequency was $500 \mathrm{~Hz}$. The logarithmic amplifier in the actgraph attmuated high amplitude signals such as those that occurred during salivation. An electrical circuit was completed between the insect, plant, and actgraph every time the insect probed into the plant tissue. The strip chart recorder moved at a speed of $2 \mathrm{~cm} / \mathrm{min}$ and graphically recorded the voltage fluctuations in the circuit. Sensitivity of the strip chart recorder was 0.1 to $0.2 \mathrm{~V}$. The 
oscilloscope was used to visualize the voltage fluctuations thereby acting as a check for the strip chart recorder. It was also useful in trouble shooting the whole system. A closedcircuit TV system connected to the EMIF was used to observe the activity of the insect.

\section{Classification of Waveforms}

Feeding activities of the insect caused different patterns or trends in voltage fluctuations. These were recorded on the graphs of the strip chart recorder and were used in determining the occurrence of the different activities and in computing the time spent for each activity.

The time spent by the insect in each activity was obtained by measuring the length of each of the waveforms corresponding to each activity on the strip chart graph. This was done by taking the length in centimeters of the waveforms and dividing it by 2 because the chart moved at a constant speed of $2 \mathrm{~cm} / \mathrm{min}$. Then the percentage of time spent on each activity was computed as $\%$ time $=$ time spent on the activity/total time of test period $\times 100$. To relate the waveforms to feeding activity, histological examinations were made of the leaf sections fed upon by the insect. These were done by allowing the insect to produce a particular waveform (through the system), after which the insect was removed from the leaf. A 1-cm "leaf portion" where the insect probed when the waveform was produced was removed and prepared for histological examination. Only leaf portions in which one probe was made were examined.

Leaf portions were cut into $25-\mu$-thick sections and stained with a safranin-light green differential stain combination. Salivary sheaths and xylem were stained red and the other tissues were green.

The mounted plant sections were examined using a compound microscope to determine the location of salivary sheath termination. The occurrence of each activity within the test period also was determined using the graphs and counter checked with the histological results.

\section{Honeydew Excretion}

The frequency of honeydew droplets excreted by the insect was observed using a closedcircuit TV system. The enlarged image of the insect on the TV screen aided in the observation of honeydew droplets as they were being excreted by the insect during ingestion. Excretion of honeydew was recorded by the use of a preprogrammed pocket computer that indicated the time at which each drop was excreted. Because the graph in the strip chart recorder moved at a constant rate of $2 \mathrm{~cm} / \mathrm{min}$, events recorded in the computer could be matched with the patterns on the strip chart recorder. The total number of honeydew droplets excreted by each insect was determined and rate per minute was computed and compared between xylem and phloem feeding.

The amount of $N$. virescens excretion on $\mathrm{R}$ and $\mathrm{S}$ cultivars was also measured using the bromocresol-filter paper method (Pathak \& Heinrichs 1982). A 1-d-old N. virescens adult was placed on a plant in each of 20 honeydew collection chambers per variety and allowed to feed for $20 \mathrm{~h}$. The honeydew excreted was collected on the filter paper and the amount was determined by measuring the area of the honeydew spots on the filter paper and expressed as square millimeters. Honeydew spots with a blue color were measured separately 
to determine the amount of phloem feeding by the insect in comparison to that of xylem feeding as indicated by yellow spots. Statistical analyses consisted of an analysis of variance with means separated with Duncan's (1955) multiple range test using the IRRISTAT Program on a personal computer.

\section{Results}

\section{Classification of Waveforms}

Six typical waveforms were recorded by the strip chart recorder through the EMIF system when the leafhopper probed and fed on the rice plant. Based on inferences from observations and other researchers' work, each type of waveform corresponded to a certain activity and location of the insect during the feeding process. These locations and probable activities were identified through histological sections of the leaf where the insect fed when the specific waveform was produced. The number of leaf tissue specimens examined for each waveform and the percentage of salivary sheaths found in the expected tissue site are indicated in Table 1.

\begin{tabular}{llccc}
\hline Table 1. Salivary sheaths found ending in expected tissue sites & \\
\hline $\begin{array}{l}\text { Expected } \\
\text { tissue site }\end{array}$ & Waveform & $\begin{array}{c}\text { Total no. } \\
\text { specimens } \\
\text { sectioned }\end{array}$ & $\begin{array}{c}\text { No. salivary } \\
\text { sheaths found in } \\
\text { expected tissue site }\end{array}$ & $\begin{array}{c}\% \text { salivary } \\
\text { sheaths found in } \\
\text { expected tissue site }\end{array}$ \\
\hline Mesophyll & R \& S & 38 & 35 & 92.1 \\
Xylem & Ix & 32 & 31 & 96.9 \\
Phloem & Ip and TIp & 25 & 23 & 92.0 \\
\hline
\end{tabular}

S-waveform (Fig. 1A)-produced during salivation, and the stylets were observed to have terminated in the mesophyll. 

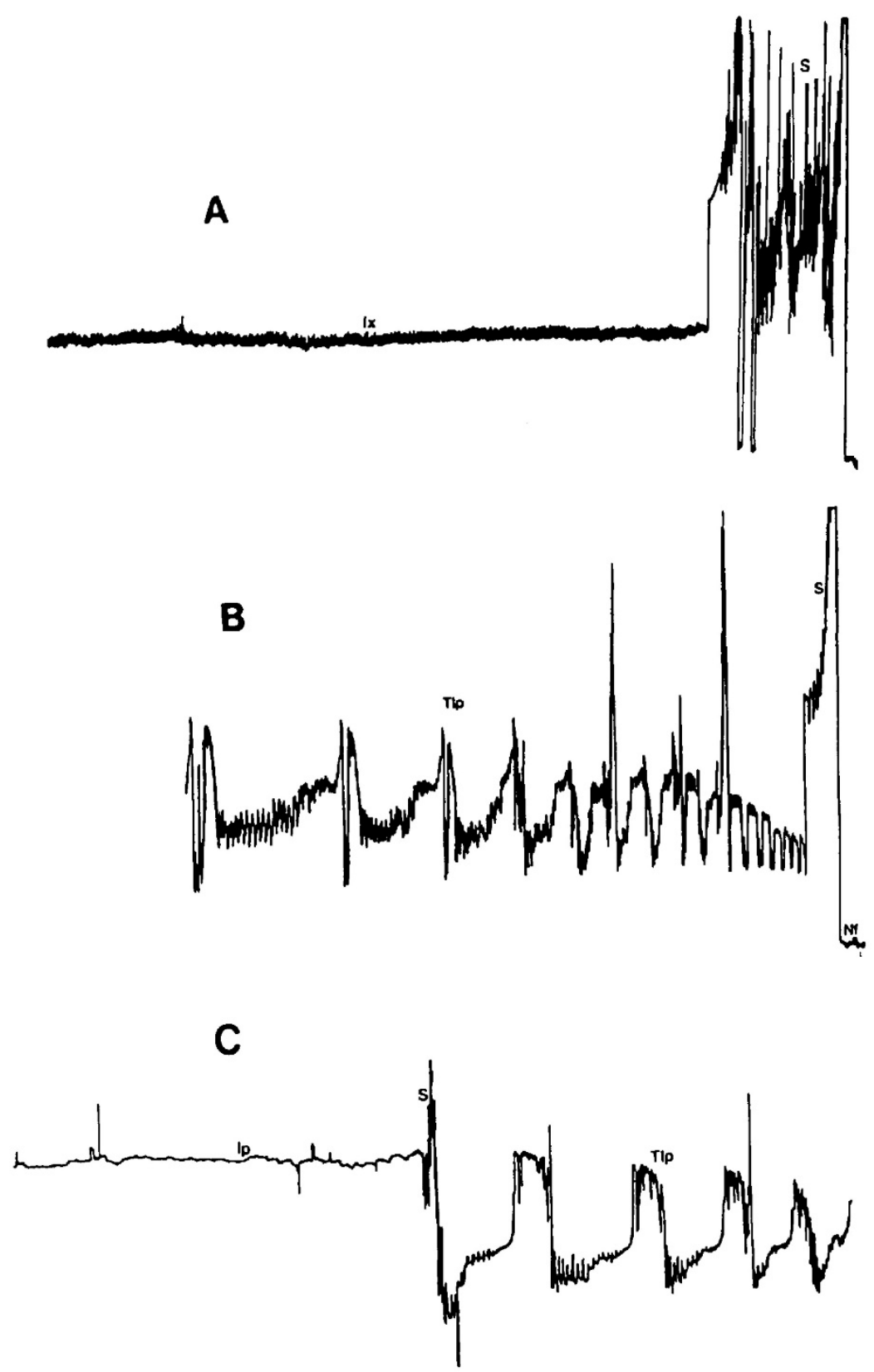

Figure 1. Waveforms recorded by the EMIF system while $N$. virescens fed on rice plants. (A) Reading from right to left, the first portion of the sequence labeled S (salivation) is actually from three probes made by the insect. The first two probes end immediately after producing some $S$ waves while the third continued into the Ix waveform (xylem feeding). (B) A probe going into a short period of S before going into a slowly expanding, wavelike pattern called TIp (trial ingestion from the phloem). (C) A portion of a sequence of waveforms showing TIp, then a very short period of S before going into sustained Ip (phloem ingestion), on susceptible plants. 
Ix-waveform (Fig. 1A) - produced as the insect was ingesting from the xylem as indicated by the salivary sheaths which terminated in the xylem vessels (Fig. 2A). During the Ix waveform, honeydew was excreted at an average of seven drops per minute.
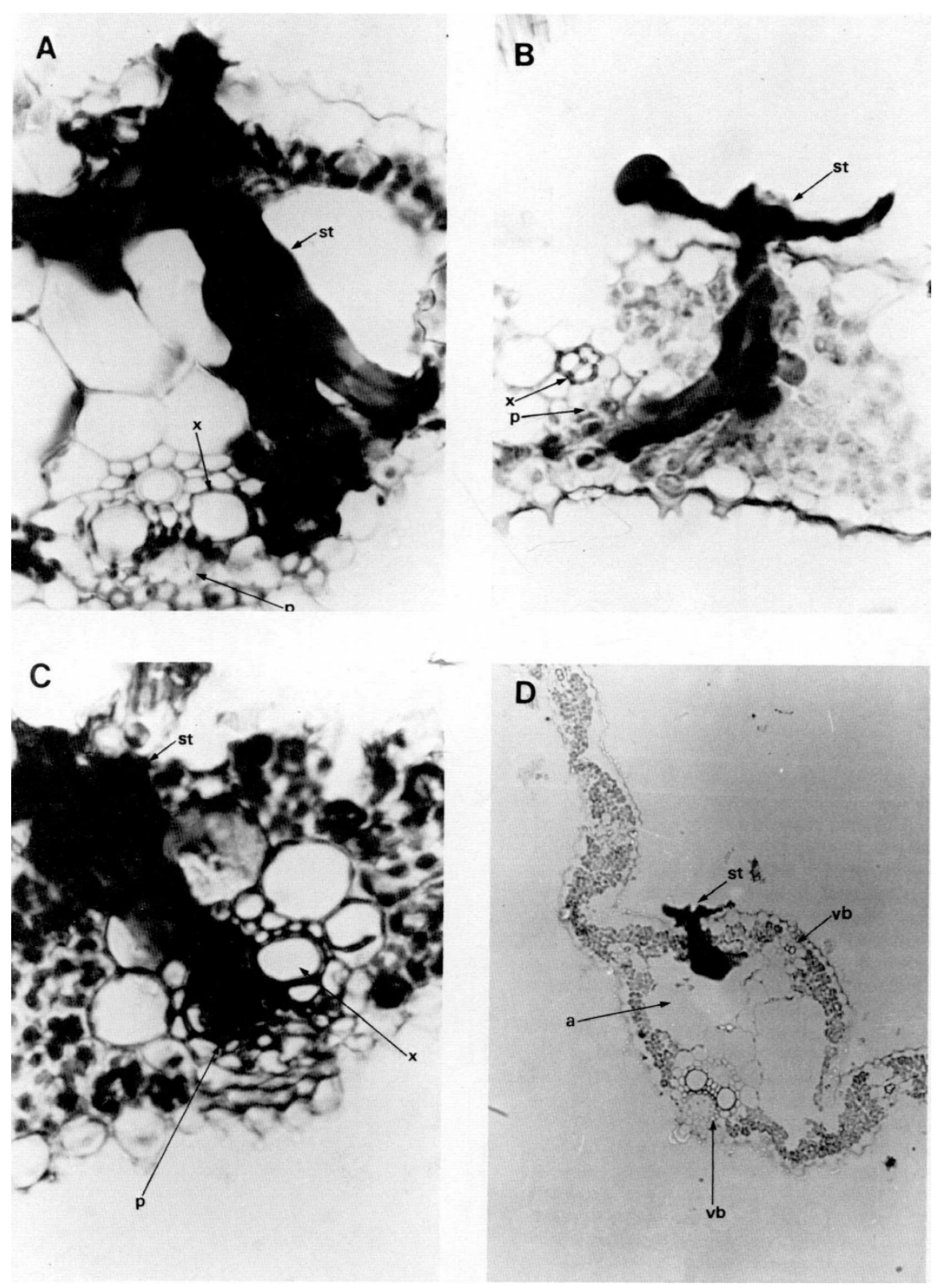

Figure 2. (A) A salivary sheath terminating in the xylem vessels (p, phloem; $x$, xylem; st, salivary sheath). (B) A salivary sheath reached the phloem tissue but there was no ingestion as indicated in the waveform produced. (C) A salivary sheath terminating in the phloem tissues with phloem sap ingestion. (D) A salivary sheath that broke into an airspace during rest periods of the insect (a, airspace; vb, vascular bundle; st, salivary sheath). 
TIp-waveform (Fig. 1B) - trial ingestion from the phloem. The salivary sheaths reached the phloem (Fig. 2B) but no sustained ingestion (> $15 \mathrm{~s}$ ) was observed. Examination of the leaf tissue indicated that $92 \%$ of the specimens had salivary sheaths in the phloem when the waveform was recorded (Table 1).

Ip-waveform (Fig. 1C) - sustained ingestion from the phloem and the salivary sheaths were observed to terminate in the phloem (Fig. 2C). Honeydew was excreted at an average of less than one drop per minute. This waveform is always preceded by the TIp waveform. However, on resistant plants only TIp was observed and no or very negligible periods of Ip activity occurred.

R-waveform (Fig. 3A)-recorded when the insect was resting with its stylets inserted into the leaf tissue, terminating in the mesophyll or air space (Fig. 2D). This activity was more commonly observed on $\mathrm{R}$ than on $\mathrm{S}$ varieties. No honeydew was excreted during this waveform and thus it is assumed that no ingestion occurred. 

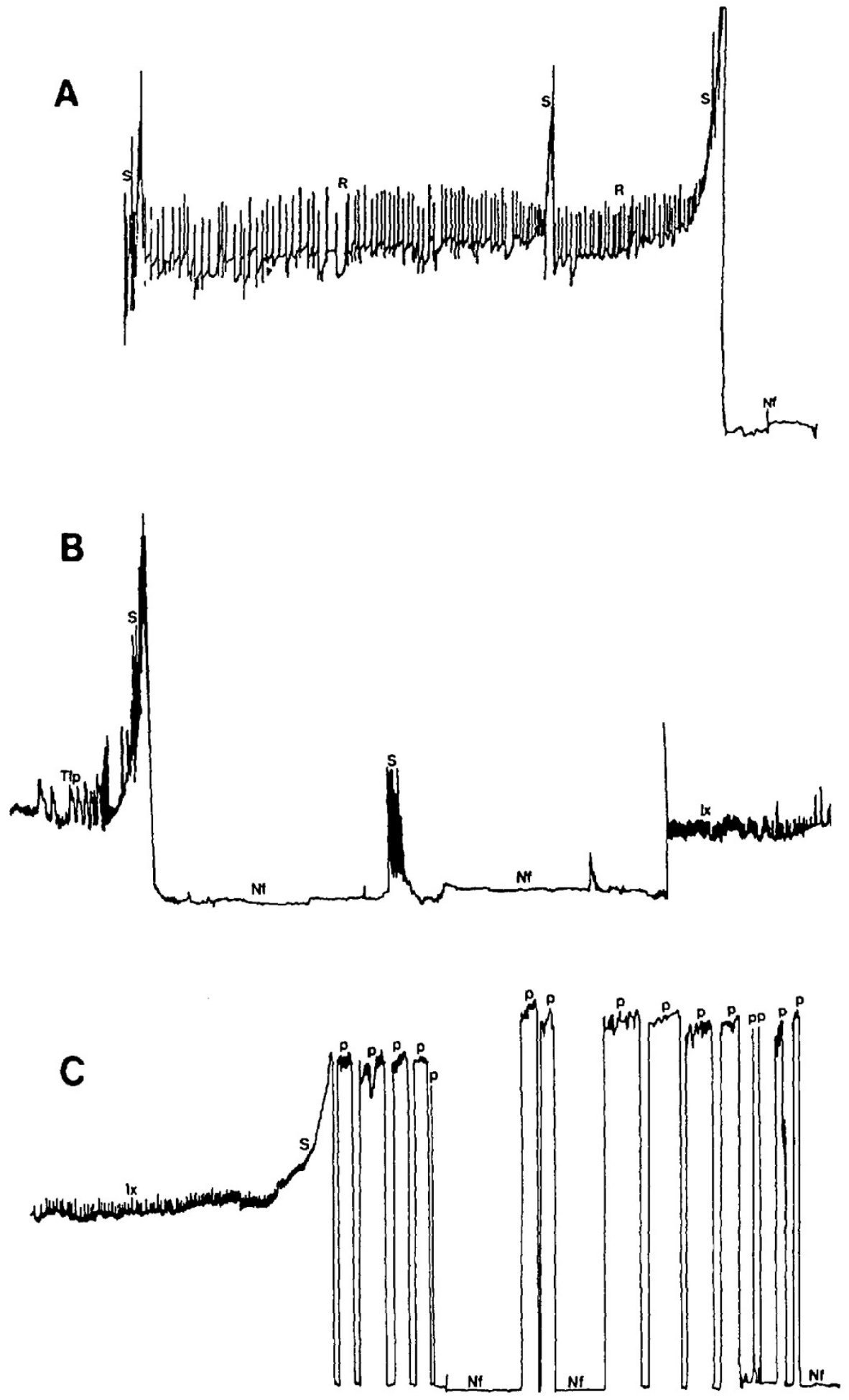

Figure 3. Caption next page 
Figure 3. Waveforms recorded by the EMIF system while $N$. virescens fed on rice plants. (A) Reading from right to left, a probe going into a short $\mathrm{S}$ (salivation) period before going into R (rest) waveforms with more short S periods in between. (B) A portion of Ix (xylem ingestion) wherein $N$. virescens when feeding withdraws its stylet from the plant resulting in a period of NF (not feeding). The short period of $S$ between the NF portions may have been an unsuccessful attempt by the insect to probe. In the end, the insect is able to make a probe, which continued into S before producing the TIp (trial ingestion from the phloem) waveform. (C) $S$ and Ix waveforms as recorded by the EMIF system with N. virescens on a resistant plant. P indicates probes made by the insect that are of short duration and with minimal S. Portions labeled NF are relatively long nonfeeding periods between probes. Short, frequent probes and long NF periods are characteristics of waveforms produced by $N$. virescens on resistant plants. The last probe goes into S, then to Ix and TIp although the recording shown does not extend to the TIp waveform.

NF waveform (Fig. 3B) - the insect was not feeding, just sitting on the leaf with stylets outside of the leaf tissue; but the rostrum may or may not have been touching the leaf surface as observed through the closed-circuit TV system.

Fig. 3C shows a typical start of probing activities of the insect on resistant varieties. The insect made 15 short duration test probes over a 12-min period before the stylets finally settled in the xylem.

Except on ASD 7 the insect changed its activity more frequently on the resistant than on the susceptible varieties as indicated by the number of probes made (Table 2). On IR64, the insect changed activity the most (39 probes with range of 16 to 94 ) during a 3-h test period, whereas on TNl, activity changed only 18 times, making only 18 probes. Although ASD7 is resistant to $N$. virescens, the insect changed activity only 20 times (probes ranged from 3 to 46) and was not significantly different from TN1. It could be noted in Figure 4 that the insects on ASD7 spent more time performing activities other than S and NF. Hence, the insects preferred to have their stylets inserted into the plant, which made them unable to make as many probes as those insects that spend more time in NF and could therefore attempt to make more probes in the plant.

Table 2. Time spent on the different activities and number of probes made by $N$. virescens when fed on rice varieties with different levels of resistance during a 3-h period (average of 10 insects)

\begin{tabular}{lcccccc}
\hline & \multicolumn{7}{c}{ Time spent, min/insect } & \\
\cline { 2 - 5 } Variety & $\mathrm{Ip}$ & $\mathrm{Tip}$ & $\mathrm{Ix}$ & $\mathrm{R}$ & $\mathrm{S}$ & No. probes/insect \\
\hline ASD7 (Hes.) & $0.0 \mathrm{~b}$ & $26.4 \mathrm{bc}$ & $40.8 \mathrm{a}$ & $47.2 \mathrm{a}$ & $32.4 \mathrm{ab}$ & $20.2 \mathrm{~b}$ \\
IR60 (Res.) & $0.0 \mathrm{~b}$ & $0.4 \mathrm{c}$ & $34.2 \mathrm{a}$ & $21.9 \mathrm{ab}$ & $39.0 \mathrm{ab}$ & $30.1 \mathrm{ab}$ \\
IR64 (Res.) & $0.0 \mathrm{~b}$ & $5.1 \mathrm{c}$ & $26.4 \mathrm{a}$ & $18.7 \mathrm{~b}$ & $53.3 \mathrm{a}$ & $38.7 \mathrm{a}$ \\
IR36 (Mod. Res.) & $0.6 \mathrm{~b}$ & $31.5 \mathrm{~b}$ & $40.8 \mathrm{a}$ & $11.4 \mathrm{~b}$ & $28.7 \mathrm{~b}$ & $23.1 \mathrm{ab}$ \\
TN1 (Sus.) & $65.2 \mathrm{a}$ & $52.7 \mathrm{a}$ & $22.8 \mathrm{a}$ & $10.5 \mathrm{~b}$ & $29.9 \mathrm{~b}$ & $17.8 \mathrm{~b}$ \\
\hline
\end{tabular}

In a column, means followed by the same letter are not significantly different at $P=0.05$; Duncan's [1955] multiple range test. Ip, phloem ingestion; TIp, trial ingestion in phloem; Ix, xylem ingestion; R, rest; S, salivation. 


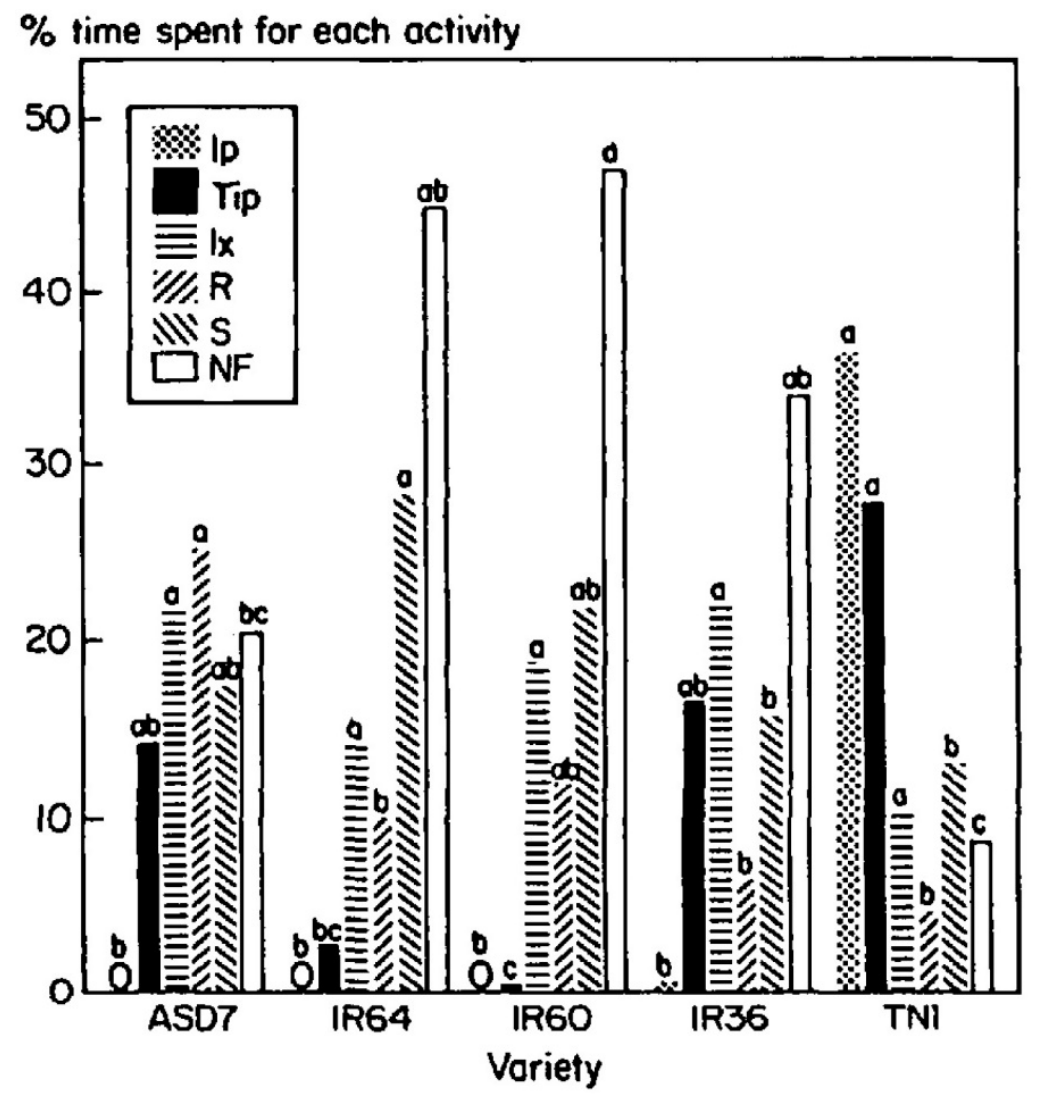

Figure 4. Percentage of time spent for each activity (or waveform) on different rice varieties. Ip, phloem ingestion; TIp, trial ingestion from the phloem; Ix, xylem ingestion; $\mathrm{R}$, rest; $S$, salivation; and NF, not feeding. Bars of the same waveforms with the same letters are not significantly different at $P=0.05$, Duncan's (1955) multiple range test.

Figure 4 shows the variations in the percentage of time spent for each activity. Although the number of probes containing each of the waveforms did not vary significantly, there were significant differences in the total duration of each waveform (Table 2).

The most striking difference among the varieties tested was in the Ip waveform where the insect had significantly more frequent and longer (Fig. 4) sustained phloem feeding on susceptible TN1 as compared with the other varieties. On TNI the insect spent most of its time feeding in the phloem, and when it was not feeding in the phloem, it preferred having its stylets in the phloem as indicated by the TIp waveforms (Fig. 4; Table 2). Furthermore, the insect spent the least time in R and NF waveforms on TN1; NF was the main waveform on the resistant IR60 and IR64 and moderately resistant IR36 (Fig. 4). Ix or xylem-feeding did not vary much among the varieties. The duration of TIp activity was higher on ASD7 than on IR60.

When we compared the waveforms that represented feeding (Ix and Ip) and other activities (TIp, R, S, and NF), it was evident that insects on TN1 spent more time ( $50 \%$ of total time) feeding, whether on the xylem or phloem, as compared with insects on the resistant 
and moderately resistant varieties. In the latter variety (IR36) only about $25 \%$ of the $3-\mathrm{h}$ test period was spent feeding (Fig. 5).

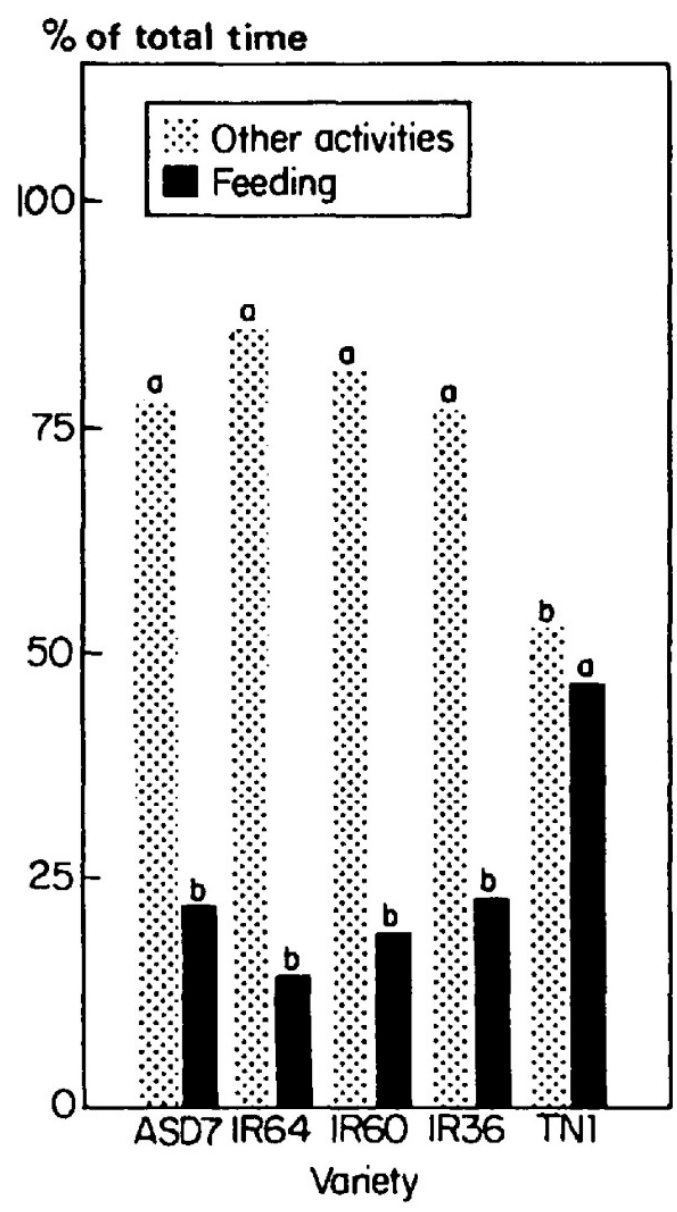

Figure 5. Percentage of the total time the cohort spent for feeding (xylem or phloem feeding) vs. other activities (TIp, R, S, and NF) on different rice varieties. Bars with the same letters are not significantly different at $P=0.05$, Duncan's (1955) multiple range test.

\section{Honeydew Excretion}

Honeydew was excreted only when the insect was feeding either from the xylem or phloem and not when stylets were located in the other tissues. The rate of excretion as indicated by the number of honeydew droplets differed significantly between xylem and phloem feeding. When the probable xylem ingestion (Ix) waveform was produced, honeydew droplets ranged from 1 to 34 drops per minute with an average of 7 drops per minute. When the probable phloem ingestion (Ip) waveform was produced, honeydew droplets averaged $<1 /$ min (range, 0.4 to 1.9). This result was observed when the insect was feeding either on a resistant or susceptible variety, although very negligible phloem feeding was observed on the resistant plants. 
The amount of honeydew excreted as measured using the bromocresol-treated filter paper showed that the total amount of honeydew did not differ much among the varieties. However, phloem feeding was significantly higher on TN1 than on the other varieties, as indicated by the blue color reaction on the filter paper (Fig. 6).

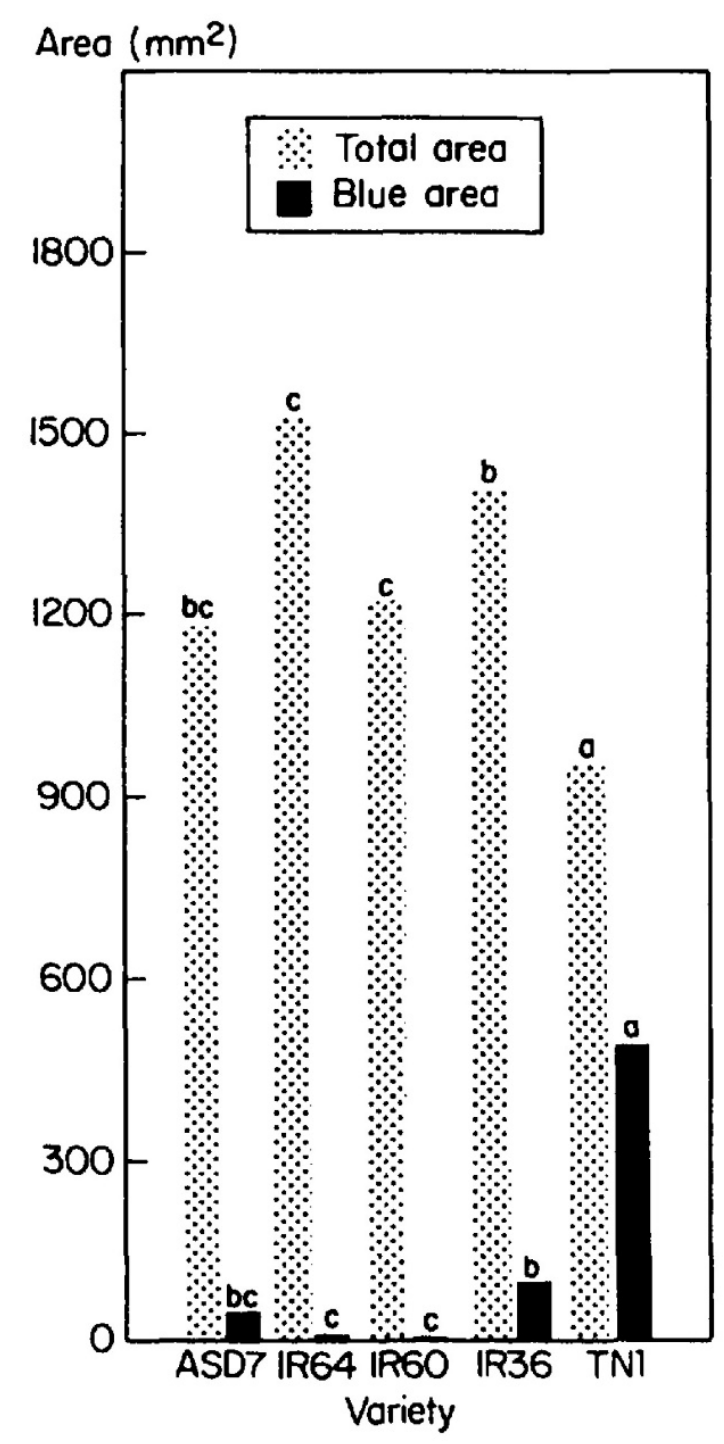

Figure 6. Amount of feeding on rice varieties as expressed in area of honeydew spot $\left(\mathrm{mm}^{2}\right)$. Bars of total area or blue area with the same letters are not significantly different at $P=0.05$, Duncan's (1955) multiple range test. 


\section{Discussion}

The EMIF device and the TV system used to study the feeding behavior of $N$. virescens provided a clear distinction among the feeding sites of the insect on susceptible and resistant varieties. Because of the ability of the system to record different waveforms indicative of the feeding activity of the insect, and by confirmation of the waveforms with histological techniques, an accurate identification of the waveforms and termination sites of the stylet sheaths was possible.

While feeding on susceptible TN1, the insect spent most of its time ingesting from the phloem (Ip), almost 2.5 times more than ingesting from the xylem. Phloem feeding on these plants ranged from 6 to $79 \mathrm{~min}$ per insect. On the resistant varieties, however, xylem ingestion was the main feeding activity lasting a maximum of $74 \mathrm{~min}$. On the moderately resistant IR36, a small amount of phloem ingestion was observed, and none was observed on the resistant varieties. The ability of the insect to produce the TIp waveform on the resistant and moderately resistant varieties showed that the stylets were able to reach the phloem, although the insect did not ingest during such activity. This observation is very important in regard to tungro virus transmission. If $N$. virescens feeds on susceptible plants infected with tungro virus for several minutes, it can readily transmit the virus to healthy plants. Although it has been reported that phloem feeding is positively correlated with tungro virus transmission (Heinrichs \& Rapusas 1984), the possibility of transmitting the virus to resistant plants during the TIp activity cannot be precluded. Higher frequency of the TIp activity on IR64 than on IR60 was observed in this study. This probably is the reason that IR64 succumbed to a higher tungro virus infection than IR60 in previous tests (H.R., unpublished data).

It was speculated by Kawabe (1985) that the sieve elements of the resistant plant contain a feeding deterrent because, although the stylets reached the sieve elements, the insect was not able to ingest phloem sap. Furthermore, a biochemical or physiological mechanism (e.g., phytoalexin, mechanical barrier) other than a feeding deterrent may exist in phloem sieve elements of resistant plants preventing $N$. virescens from ingesting phloem sap.

Detailed studies on biochemical bases of resistance are now being undertaken. We hope that these studies will provide information as to the factors determining the $N$. virescens feeding behavior on resistant varieties.

Khan \& Saxena (1985) conducted a study similar to ours using a DC monitor rather than AC. Three common rice varieties (resistant ASD7, moderately resistant IR36, and susceptible TN1) were used in the two studies. Khan and Saxena reported five times as many probes on ASD7 and IR36 as we reported, but the number of probes on TN1 was similar in the two studies. This difference may be due to the high voltage $(1.5 \mathrm{~V})$ of the DC monitor in their study compared with the low voltage $(100-500 \mathrm{mV})$ in our study. The high voltage may cause increased irritability of the insects resulting in repeated, short test probes on less acceptable resistant plants.

Although our study and that of Khan and Saxena conclude that N. virescens primarily ingests phloem sap in susceptible varieties and xylem sap in resistant varieties, the waveforms produced in the two studies differ. In their study the voltage levels produced during xylem ingestion were high and voltage levels produced during phloem feeding were low, 
whereas we obtained opposite results in our study. Khan and Saxena classified their DC waveforms for $N$. virescens according to Chang's (1978) description of AC-obtained waveforms using sugarcane leafhoppers Perkinsiella saccharicida (Kirkaldy) as the test insect. The different waveforms obtained using AC and DC monitors may be due to the differences between the two systems (e.g., the supplied potential, input resistance of the amplifier, and the sensitivity of the recording equipment) (Kimmins 1989).

Acknowledgment - The authors express their sincere thanks to Susan Valdez of the Department of Entomology, IRRI, for assisting in the EMIF and histological work.

\section{References Cited}

Auclair, J. L., E. Baldos \& E. A. Heinrichs. 1982. Biochemical evidence of the feeding sites of the leafhopper, Nephotettix virescens within susceptible and resistant rice plants. Insect Sci. Appl. 3: 29-34.

Cabunagan, R. C., E. R. Tiongco \& H. Hibino. 1984. Reaction to rice tungro virus (RTV) complex as influenced by insect pressure. Int. Rice Res. Newsl. 9(6): 13.

Chang, V. C. S. 1978. Feeding activities of the sugarcane leafhopper: identification of electronically recorded waveforms. Ann. Entomol. Soc. Am. 71: 31-36.

Duncan, D. B. 1955. Multiple range and multiple F tests. Biometrics 11: 1-42.

Heinrichs, E. A. \& H. R. Rapusas. 1984. Feeding activity of the green leafhopper (GLH) and tungro (RTV) infection. Intl. Rice Res. Newsl. 9(5): 15.

Hodges, L. R. \& D. L. McLean. 1969. Correlation of the transmission of bean yellow mosaic virus with salivation activity of Acyrthosiphon pisum (Homoptera: Aphididae). Ann. Entomol. Soc. Am. 62: 1398-1401.

Kawabe, S. 1985. Mechanism of varietal resistance to the rice green leafhopper (Nephotettix cincticeps Uhler). J. Agric. Res. Q. 19(2): 115-124.

Kawabe, S. \& D. L. McLean. 1982. Electronic measurement of probing activities of the green leafhopper of rice. Entomol. Exp. Appl. 27: 77-82.

Kawabe, S., D. L. McLean, S. Tatsuki \& T. Ouchi. 1981. An improved electronic measurement system for studying ingestion and salivation activities of leafhoppers. Ann. Entomol. Soc. Am. 74: 222-225.

Khan, Z. R. \& R. C. Saxena. 1985. Mode of feeding and growth of Nephotettix virescens (Homoptera: Cicadellidae) on selected resistant and susceptible rice varieties. J. Econ. Entomol. 78: 583-587.

Kimmins, F. M. 1989. Electrical penetration graphs from Nilaparvata lugens on resistant and susceptible rice varieties. Entomol. Exp. Appl. 50: 69-79.

McLean, D. L. 1977. An electrical measurement system for studying aphid probing behavior, pp. 277-290. In K. F. Harris \& K. Maramorosch [eds.], Aphids as virus vectors. Academic, San Francisco.

McLean, D. L. \& M. G. Kinsey. 1964. A technique for electronically recording aphid feeding and salivation. Nature 202: 1358-1359.

McLean, D. L. \& M. G. Kinsey. 1965. Identification of electronically recorded wave patterns associated with aphid salivation and ingestion. Nature 205: 1130-1131.

Nielson, M. W. \& H. Don. 1974. Probing behavior of biotypes of the spotted alfalfa aphid on resistant and susceptible alfalfa clones. Entomol. Exp. Appl. 17: 477-486.

Pathak, P. K. \& E. A. Heinrichs. 1982. Bromocresol green indicator for measuring feeding activity of Nilaparvata lugens on rice varieties. Philipp. Entomol. 5: 209-212. 
Saxena, R. C. \& Z. R. Khan. 1985. Electronically recorded disturbance in feeding behavior of Nephotettix virescens (Homoptera: Cicadellidae) on neem oil treated rice plants. J. Econ. Entomol. 78: 222-226.

Velusamy, R. \& E. A. Heinrichs. 1986. Electronic monitoring of feeding behavior of Nilaparvata lugens (Homoptera: Delphacidae) on resistant and susceptible rice cultivars. Environ. Entomol. 15: 678682. 